\section{Response to: 'Paracetamol: is all the concern valid?' by Schwarz and Mullins}

We thank Drs Schwarz and Mullins for their comments ${ }^{1}$ on our paper, ${ }^{2}$ and we agree with many of their points. The absolute risks of the studied adverse events were small, and paracetamol still has a better adverse event profile than traditional nonsteroidal anti-inflammatory drugs (NSAIDs) or opioids. However, we would like to highlight that there are also nonpharmacological alternatives for chronic pain conditions, especially those of the musculoskeletal system: muscle strengthening, increased activity and weight loss if overweight. ${ }^{3}$

We appreciate that biases (including non-complete adjustment for confounders, narrow population of the included studies and the reliance on self-report and paracetamol prescription as methods to calculate the total ingested amount of paracetamol) make the observational data in our review difficult to interpret. We also appreciate, and highlighted in our discussion, the potential for confounding by indication and suggest that increasing doses of paracetamol might reflect sicker patients and might be a marker for those using increasing doses of over-the-counter NSAIDs. Four included studies did not adjust for concomitant NSAID use, ${ }^{4-7}$ and channelling bias may lead those patients deemed unsuitable for NSAID therapy to be prescribed paracetamol as a 'safer' alternative. Those studies that did control for other analgesic use all showed dose-response relationships for their adverse event outcomes. We specified a priori if cohort-level evidence was found for an adverse event outcome, case-control evidence was not considered, though noted evidence from the case-control literature supporting the doseresponse seen in the current review. ${ }^{8}$

We agree that the overall GRADE rating was very low for all outcomes, but would highlight that as all studies included were observational, the GRADE system of quality rating per outcome begins at 'low' quality, which is based solely on a study's observational design, and does not take into consideration that observational studies are the most appropriate study design to assess the risk of the studied long-term adverse event outcomes.

Given recent publications regarding paracetamol's weak peripheral anti-inflammatory mode of action, ${ }^{9}$ we believe that data demonstrating side effects potentially reflecting this should be published. A recent well designed randomised controlled trial reporting equivalent blood loss with paracetamol and ibuprofen strengthens our belief. ${ }^{10}$ Of course, clinicians first need to consider the efficacy in chronic painful musculoskeletal conditions, ${ }^{11} 12$ but be mindful of the fact a paracetamol prescription is not one with zero risk.

\section{Emmert Roberts, ${ }^{1}$ Philip G Conaghan ${ }^{2}$}

${ }^{1}$ Department of Psychological Medicine, Institute of Psychiatry, Psychology \& Neuroscience, King's College London, UK
${ }^{2}$ Leeds Institute of Rheumatic and Musculoskeletal Medicine, University of Leeds and NIHR Leeds Musculoskeletal Biomedical Research Unit, Leeds UK

Correspondence to Dr Emmert Roberts, Department of Psychological Medicine, Institute of Psychiatry, Psychology \& Neuroscience, King's College London, Weston Education Centre, 10 Cutcombe Rd, London SE5 9RJ, UK; emmert.roberts@slam. nhs.uk

Competing interests None declared.

Provenance and peer review Commissioned; internally peer reviewed.

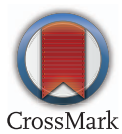

To cite Roberts E, Conaghan PG. Ann Rheum Dis 2015;74:e49.

Received 7 April 2015

Accepted 11 April 2015

Published Online First 28 April 2015

\section{S Linked}

http://dx.doi.org/10.1136/annrheumdis-2015-207644

Ann Rheum Dis 2015;74:e49. doi:10.1136/annrheumdis-2015-207691

\section{REFERENCES}

1 Schwartz E, Mullins ME. Paracetamol: is all the concern valid? Ann Rheum Dis 2015; 74:e48.

2 Roberts E, Delgado Nunes V, Buckner S, et al. Paracetamol: not as safe as we thought? A systematic literature review of observational studies. Ann Rheum Dis 2015. Published Online First 2 Mar 2015. doi:10.1136/annrheumdis-2014-206914

3 National Institute for Health and Care Excellence. Osteoarthritis: Care and management in adults. (Clinical Guideline CG177). 2014. http://www.nice.org.uk/ guidance/cg177

4 de Vries F, Setakis E, van Staa TP, et al. Concomitant use of ibuprofen and paracetamol and the risk of major clinical safety outcomes. Br I Clin Pharmacol 2010;70:429-38.

5 Lipworth L, Friis S, Mellemkjaer L, et al. A population-based cohort study of mortality among adults prescribed paracetamol in Denmark. J Clin Epidemiol 2003;56:796-801.

6 Dedier J, Stampfer M, Hankinson S, et al. Nonnarcotic analgesic use and the risk of hypertension in US women. Hypertension 2002;40:604-8.

7 Evans $M$, Fored CM, Bellocco R, et al. Acetaminophen, aspirin and progression of advanced chronic kidney disease. Nephrol Dial Transplant 2009;24:1908-18.

8 Garcia Rodriguez LA, Hernandez-Diaz S. Relative risk of upper gastrointestinal complications among users of acetaminophen and nonsteroidal anti-inflammatory drugs. Epidemiology 2001;12:570-6.

9 Hinz B, Brune K. Paracetamol and cyclooxygenase inhibition: is there a cause for concern? Ann Rheum Dis 2012;71:20-5.

10 Doherty M, Hawkey C, Goulder M, et al. A randomised controlled trial of ibuprofen, paracetamol or a combination tablet of ibuprofen/paracetamol in community-derived people with knee pain. Ann Rheum Dis 2011;70:1534-41.

11 Zhang W, Nuki G, Moskowitz RW, et al. OARSI recommendations for the management of hip and knee osteoarthritis: part III: changes in evidence following systematic cumulative update of research published through January 2009. Osteoarthritis Cartilage 2010;18:476-99.

12 Machado G, Maher $\mathrm{C}$, Ferreira $\mathrm{P}$, et al. Efficacy and safety of paracetamol for spinal pain and osteoarthritis: systematic review and meta-analysis of randomised placebo controlled trials. BMJ 2015;350:h1225. 